\title{
The $\alpha$-tubulin gene family in wheat (Triticum aestivum L.) and differential gene expression during cold acclimation
}

\author{
Mohammed Ridha Farajalla and Patrick J. Gulick
}

\begin{abstract}
The $\alpha$-tubulins and $\beta$-tubulins are the major constituents of microtubules, which have been recognized as important structural elements in cell growth and morphogenesis, and, recently, for their role in regulation and signal transduction. We have identified 15 full-length cDNAs for the members of the $\alpha$-tubulin gene family in hexaploid bread wheat (Triticum aestivum L.). The genes were clustered into 5 homeologous groups of 3 genes. Representatives of the 5 homeologous groups were mapped to different chromosome arms, and the genome of origin was determined for each gene. Changes in mRNA levels were observed for the paralogous members of the gene family during cold acclimation. Three members of the family had initial decreases in mRNA levels in response to cold treatment, which were followed by increases, each with a different pattern of reinduction. One gene-family member showed increased mRNA for up to $14 \mathrm{~d}$ during cold acclimation and had decreased levels after $36 \mathrm{~d}$ of cold treatment; a fifth paralogous member of the gene family had slowly declining mRNA levels up to $36 \mathrm{~d}$. Subtle differences in the level of gene expression among homeologs and large differences among paralogs were detected by comparing the relative abundance of wheat $\alpha$-tubulin expressed sequence tags (ESTs) in public databases.
\end{abstract}

Key words: alpha tubulin, cold acclimation, gene expression, gene family, allopolypoid, homeologs.

Résumé : Les $\alpha$ - et les $\beta$-tubulines sont les principales composantes des microtubules, lesquels sont reconnus constituer des composantes structurales importantes pour la croissance cellulaire, la morphogenèse et, récemment, pour leur rôle dans la régulation et la transduction des signaux. Les auteurs ont identifié $15 \mathrm{ADNc}$ complets pour des membres de la famille des $\alpha$-tubulines chez le blé tendre hexaploïde (Triticum aestivum L.). Les gènes forment 5 groupes de 3 gènes homéologues. Des représentants des 5 groupes d'homéologues ont été assignés à différents bras chromosomiques et le génome d'origine de chaque gène a été déterminé. Des changements dans l'abondance des ARNm ont été observés pour les paralogues durant l'acclimatation au froid. Trois gènes montraient une diminution initiale en réponse au traitement au froid suivie d'un accroissement mais selon une cinétique différente dans le cas de la ré-induction. Un gène a montré un accroissement de son ARNm jusqu'à 14 jours au cours de l'acclimatation et présentait un niveau réduit d'ARNm après 36 jours au froid. Le cinquième gène a montré une diminution lente de l'abondance de l'ARNm jusqu'à 36 jours. Des différences subtiles dans le niveau d'expression parmi les homéologues et des différences importantes entre paralogues ont été détectées par comparaison des abondances relatives des EST correspondant à des $\alpha$-tubulines dans les banques de données publiques.

Mots-clés : alpha-tubuline, acclimatation au froid, expression génique, famille multigénique, allopolyploïde, homéologues.

[Traduit par la Rédaction]

\section{Introduction}

Cold tolerance in crops is a multigenic trait and an important factor that limits the geographic distribution of crop cultivation (Thomashow 1999). Winter wheat is one of the most cold-tolerant crop species and is an excellent model to study freezing tolerance. High levels of cold tolerance are achieved only after a period of acclimation that requires

Received 24 July 2006. Accepted 13 December 2006. Published on the NRC Research Press Web site at genome.nrc.ca on 12 June 2007.

Corresponding Editor: G. Scoles.

M. Ridha Farajalla and P.J. Gulick. ${ }^{1}$ Department of Biology, Science Pavilion, Concordia University, 7141 Sherbrooke Street W, Montréal, QC H4B 1R6, Canada.

${ }^{1}$ Corresponding author (e-mail: pgulick@alcor.concordia.ca). growth at low but above-freezing temperatures. During cold acclimation, the expression levels of many genes are known to change; it has been reported that a number of genes are differentially regulated between cold-tolerant and less tolerant cultivars (Thomashow 1998; Gulick et al. 2005; Tremblay et al. 2005; Oono et al. 2006). The study of the regulatory and signaling elements that control the changes of gene expression is essential for the understanding of cold acclimation and the genetic basis of cold tolerance. Microtubules are key elements of the cytoskeleton and have recently come to be appreciated for their role in signaling and regulation. They are critical conduits for cellular trafficking and can serve as a template for the interaction of signaling proteins (Camilleri et al. 2002). These structures, which are composed of $\alpha$-tubulin and $\beta$-tubulin, go through a transient disorganization followed by a major rearrangement in root cortical cells during cold acclimation (Jian et al. 1989). A comparison of 3 cultivars of winter wheat (Triticum aesti- 
vum L.) that have different degrees of freezing tolerance found that a rapid but transient partial disassembly of the microtubules and the formation of cold-stable microtubules occurred in tolerant but not in sensitive cultivars (Abdrakhamanova et al. 2003). The provocation of transient microtubule disassembly by a pulse treatment with the herbicide pronamide could increase freezing tolerance of treated plants. It has been reported that the appearance of cold-stable microtubules is accompanied by a reduced abundance of type TUA1/2 $\alpha$-tubulin isotypes (Abdrakhamanova et al. 2003). The intimate association of microtubules with the plasma membrane, the major platform of signal perception and transduction, suggests that microtubules are targets of various switches and signals (Gilroy and Trewavas 2001; Wasteneys and Galway 2003). The microtubule surface is known to be associated with motor proteins, GDP/GTPbinding proteins, structural microtubule-associated proteins, regulatory kinases, and phosphatases (Wasteneys 2003). The changes in microtubules observed during cold acclimation in wheat and the extensive investigation of microtubules in mammalian systems (Dent et al. 2003; Rodriguez et al. 2003) suggest that microtubules play an integral role in the signaling that enables plants to adapt to environmental changes. The identification of a large number of RNAbinding and signaling proteins that were shown to be microtubule-binding proteins in Arabidopsis supports this hypothesis (Chuong et al. 2004). In work describing proteinprotein interaction networks in wheat, we have found specific interaction between a member of the $\alpha$-tubulin gene family and a cold-acclimation-induced receptor kinase (Tardif et al. 2007). To investigate the role of microtubules in signalling during cold acclimation in wheat, we characterized the structure of the $\alpha$-tubulin family. Only a single fulllength cDNA sequence for a wheat $\alpha$-tubulin was previously available in GenBank, although expressed sequence tag (EST) sequences in dbEST indicate the existence of many other gene-family members in Triticum. In this study, we identified the 15 members of the $\alpha$-tubulin gene family in hexaploid bread wheat (Triticum aestivum), characterized changes in the level of mRNA expression for the genefamily members in response to cold acclimation, and determined the chromosome location for representatives of each homeologous group.

\section{Materials and methods}

\section{Plant material and growth conditions}

Spring wheat (T. aestivum 'Quantum') seeds were germinated in a 1:1 mixture of vermiculite and soil and grown for 7 days with a $16 \mathrm{~h}$ photoperiod. White fluorescent and incandescent lighting was combined to provide a light intensity of $196 \mu \mathrm{mol} \mathrm{m} \mathrm{m}^{-2} \mathrm{~s}^{-1}$. The temperature was maintained at $20 \pm 1{ }^{\circ} \mathrm{C}$. Seven-day-old seedlings were cold acclimated by lowering the growth temperature to $4{ }^{\circ} \mathrm{C}$, and plants were harvested after $1,3,6,14$, and 36 days. Control seedlings were 8-day-old plants grown at $20 \pm 1{ }^{\circ} \mathrm{C}$.

\section{DNA sequencing and analysis}

cDNA clones for $15 \alpha$-tubulins were identified in the EST database developed in the Genome Canada program Functional Genomics of Abiotic Stress (FGAS). DNA sequencing was performed at the Genome Québec Innovation Centre at McGill University in Montréal. The DNA sequences for the T. aestivum $\alpha$-tubulins reported in this article have been deposited in GenBank with consecutive accession Nos., DQ435659 through DQ435673. Multiple-sequence comparison was done with Clustal W (Thompson et al. 1994) to cluster gene-family members in wheat and compare them with $\alpha$-tubulin sequences in rice, barley, and Arabidopsis. Gene-specific primers were designed for individual genefamily members chosen from polymorphic regions near the end of the coding region and the $3^{\prime}$ UTR with the aid of Primer 3 software (http://frodo.wi.mit.edu/cgi-bin/primer3/ primer3_www.cgi).

\section{Gene mapping to chromosome arms}

Cytogenetic stocks of the hexaploid cultivar T. aestivum 'Chinese Spring' were used for the chromosomal mapping of gene-family members. The selected set included 19 nullisomic-tetrasomic lines (Sears 1954, 1966), which have 1 chromosome pair substituted by a homeologous pair of chromosomes. Selected ditelosomic lines, which are missing specific chromosome arms (Sears and Sears 1978), and partial chromosome-arm deletion lines (Endo and Gill 1996) were used to confirm the chromosome position of genes and to determine the chromosomal arm for the locus. DNA from the cytogenetic stocks was screened with PCR using gene-specific primers. The gene-specific primers for each gene were as follows: Ta_TUBA-1-3, forward GCGCCTCTCGGTTGATTAC, reverse GGTTTTGATGGTTGCGACT; Ta_TUBA-2-3, forward TCAGGTCATTTCATCACTGACA, reverse CACCAGGAGGCAGGCTTA; Ta_TUBA-3-1, forward CTGGTGCCCTACCCAAGA, reverse GGCGGGGGTCACACTTT; Ta_TUBA-3-2, forward TGAATGTTGATGTGAACGAGTTT, reverse TAGACGAAGGGACGCTTGA; Ta_TUBA-3-3, forward GAGGTGAGGACTGGCACCTAT, reverse AGGTTGGTCTGGAATTCGTTC; Ta_TUBA-4-3, forward GCCGACAACTGCACTGGA, reverse CGTCCTCCTCGCCATCA; Ta_TUBA5-1, forward GTGTCCGACTGGGTTCAAGT, reverse CCCTGCAATTTCTCGCAGT; Ta_TUBA-5-2, forward CCTTACAACAGCGTGCTCTCA, reverse CACAACACTGCCACCCAAT; and Ta_TUBA-5-3, forward GCCAGCTCTTCCATCCA, reverse AGAGCGCACACTTGATCC.

\section{RNA isolation}

Samples of a pool of approximately 30 seedlings were taken for each time point from treatment and control plants. The samples were of the aerial part of the plant and included the leaves and the meristematic crown. Samples were ground in a mortar and pestle with liquid nitrogen, and 4-5 $\mathrm{g}$ of tissue was used to extract total RNA. RNA was purified with TRIZOL reagent ( $5 \mathrm{~mL}$ per $1 \mathrm{~g}$ of tissue), in accordance with the manufacturer's protocol (Invitrogen Life Technologies, Burlington, Ont.).

\section{RT-PCR measurement of transcript level of selected genes}

Total RNA samples were treated with DNaseI (Ambion, Inc., Austin, Tex.). Samples were quantified by spectrometer. A total of $5 \mu \mathrm{g}$ of RNA was used for reverse transcription, using Invitrogen SuperscriptII and an oligo-dT primer 
Fig. 1. Phylogram based on amino acid sequence identities of the $\alpha$-tubulins of barley (Hv), hexaploid wheat (Ta), rice (Os), and Arabidopsis (At).

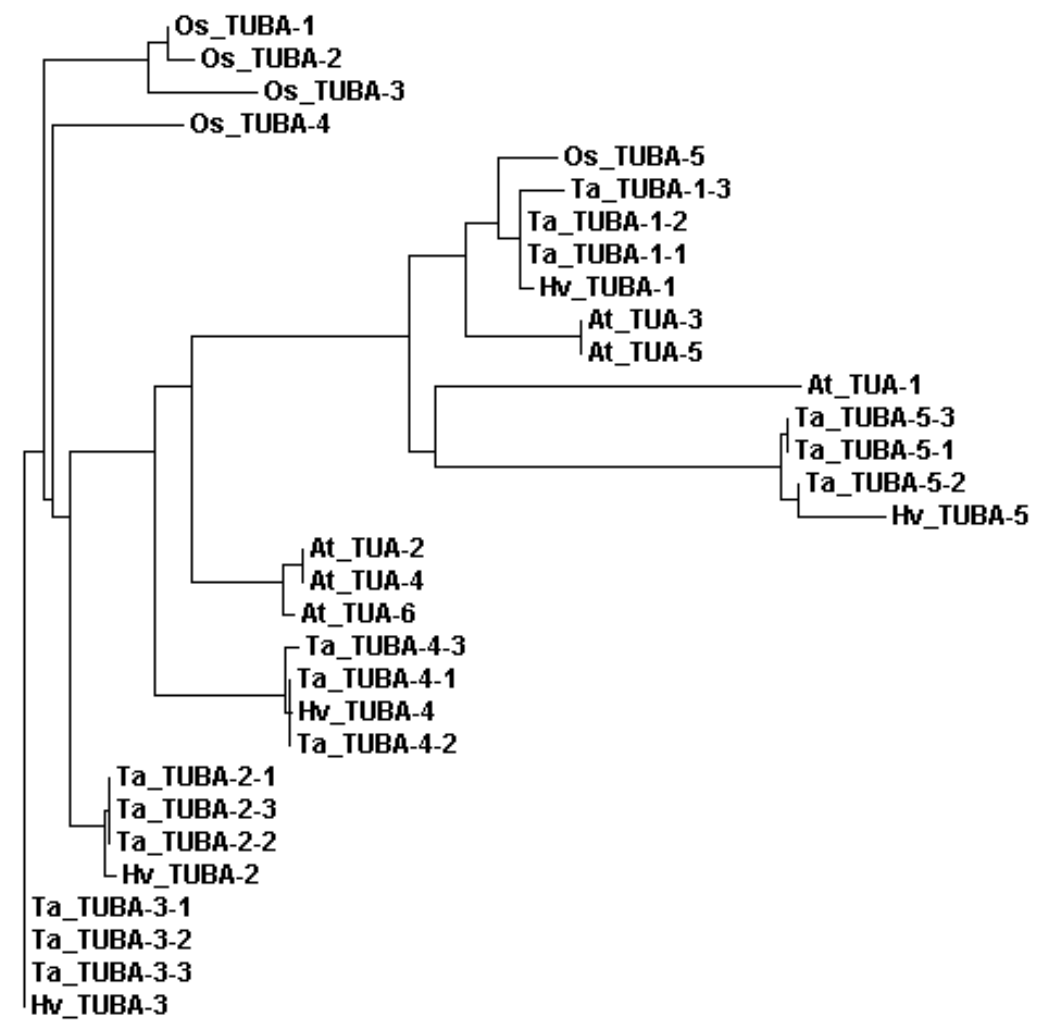

(Invitrogen Canada, Burlington, Ont.) in accordance with the manufacturer's recommendation. A one-fiftieth volume of each cDNA was used for PCR amplification with Taq DNA polymerase (MBI Fermentas, Burlington, Ont.) under the following conditions: $95{ }^{\circ} \mathrm{C}$ for $2 \mathrm{~min}$, then 30 to 35 cycles at $94{ }^{\circ} \mathrm{C}$ for $30 \mathrm{~s}, 58{ }^{\circ} \mathrm{C}$ for $30 \mathrm{~s}$, and $72{ }^{\circ} \mathrm{C}$ for $1 \mathrm{~min}$, followed by $72{ }^{\circ} \mathrm{C}$ for $7 \mathrm{~min}$ and a pause at $4{ }^{\circ} \mathrm{C}$. Expression of specific gene-family members was determined with the gene-specific primers listed above. Ubiquitin cDNA was amplified as an internal control (Yan et al. 2003). To rule out DNA contamination of the RNA samples, control PCR reactions were run with RNA samples that had not been reverse transcribed. Gene expression for $T a \_T U B A-4-3$ and $T a \_T U B A-2-3$ was assayed in replicate sets of RNA and patterns of gene expression were similar to those observed in the original RNA set. This confirmed that there were no anomalies in RNA isolation or in reverse transcriptase (RT)-PCR.

\section{Relative abundance of $\alpha$-tubulin ESTs in GenBank}

The relative abundance of ESTs from individual genefamily members was measured with a MegaBlast search of the NCBI "EST other" database limited to T. aestivum, which totaled 855600 sequences (Oct. 2006). The searches were conducted with the coding region of the $\alpha$-tubulin cDNA sequences, with the MegaBlast word-size parameter set to 64 and alignments set to 5000. Hits with sequences from the FGAS EST program were excluded, and EST sequences with a minimum overlap of 100 nucleotides and $99 \%$ identity with the search sequence were tabulated for each gene-family member.

\section{Results}

The $\alpha$-tubulin gene family in $T$. aestivum

Full-length cDNA clones for 15 members of the $\alpha$-tubulin gene family were identified within the FGAS clone collection. cDNA clones for all members of the gene family were fully sequenced, and the full coding region was identified. There were 3 length variants among the genes; they encoded proteins of 449, 450, or 451 amino acids. Sequence similarity was used to group gene-family members into 5 groups that likely comprise homeologs from 3 ancestral genomes of hexaploid wheat (Fig. 1). DNA sequence comparison indicated that the 5 groups of 3 genes each have high sequence similarity to 1 of the $5 \alpha$-tubulins identified in diploid barley (Hordium vulgare), a closely related species and member of the Triticae. Gene-family members were assigned a 2-digit number; the first digit is for the homeologous group and has the same number that was used for the barley orthologs, and the second digit (1, 2, or 3) distinguishes each member of the homeologous group (Fig. 1). The second digit is a tentative designation that corresponds to the genome of origin $\mathrm{A}, \mathrm{B}$, or $\mathrm{D}$, which will be shown below. Nucleic acid sequence similarity within the coding region within homeologous groups was $98 \%$ to $97 \%$ and sequence similarity between homeologous groups ranged from $94 \%$ to $77 \%$. Amino acid sequence similarity within homeologous groups was 99\%-100\% and between groups it ranged from $98 \%$ to $87 \%$. Sequence similarity in the $5^{\prime}$ and $3^{\prime}$ UTR of wheat $\alpha$-tubulins is lower than that within the coding region and is characterized by a number of small deletions or insertions. There is a higher sequence similarity 
Fig. 2. Mapping of the $\alpha$-tubulin genes to chromosomes after PCR amplification of DNA from nulli-tetrasomic lines: (A) Ta_TUBA-1-3 is on chromosome 2D; (B) Ta_TUBA-2-3 is on chromosome 1D; (C) Ta_TUBA-3-3 is on chromosome 4D; (D) Ta_TUBA-4-3 is on chromosome 5D; and (E) Ta_TUBA-5-3 is on chromosome 4D.
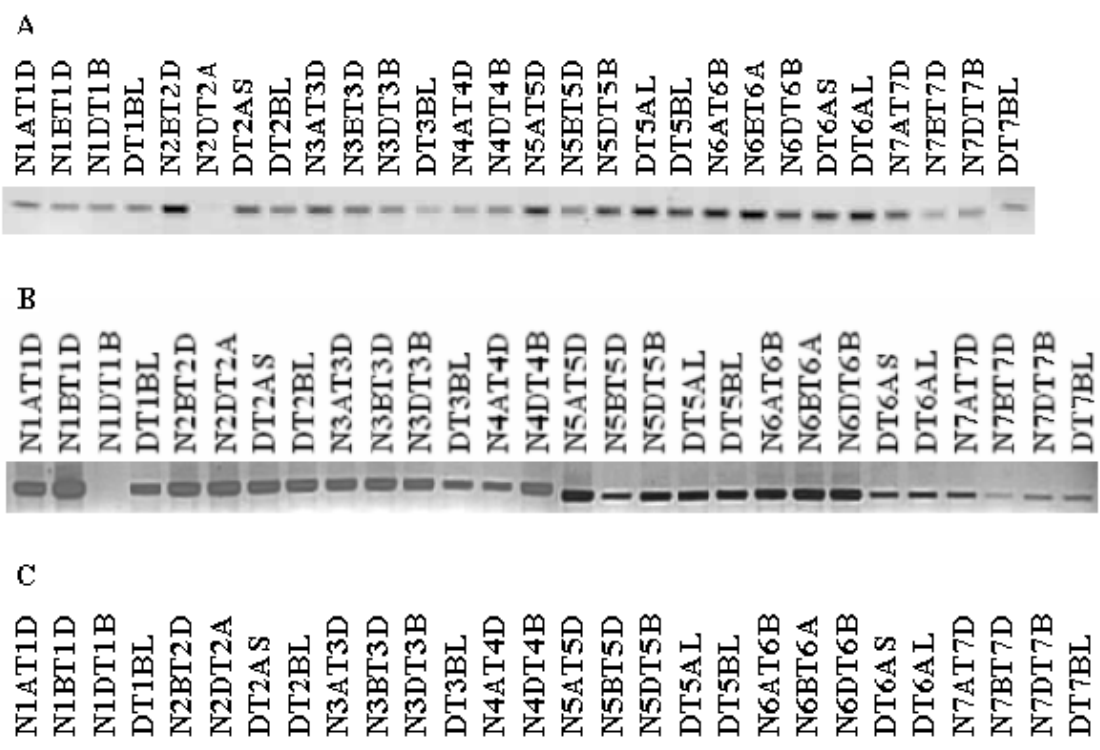

GE

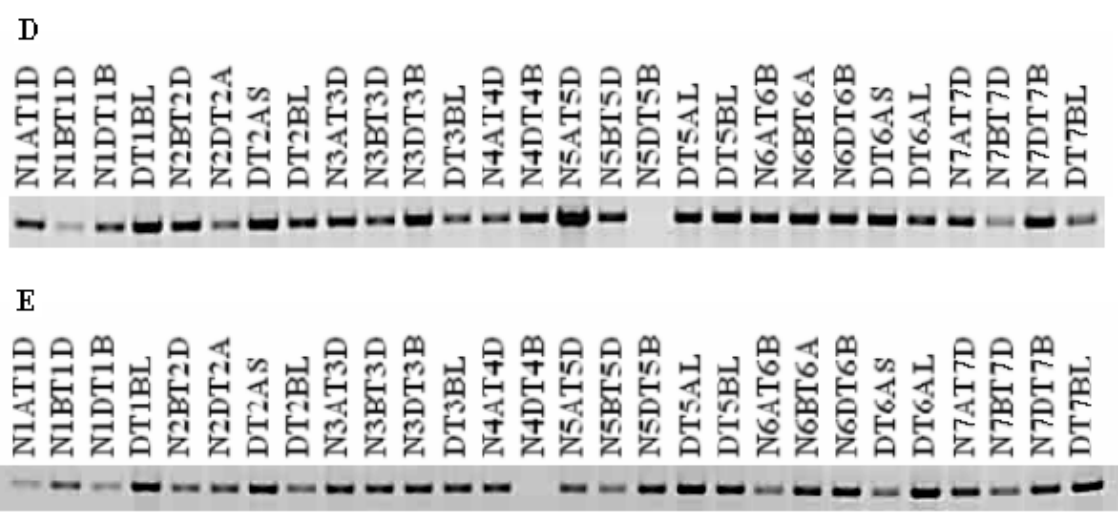

between orthologous $\alpha$-tubulin genes of wheat and barley than between paralogs within the gene family, suggesting that the $\alpha$-tubulin gene family originated before the divergence of the wheat and barley lineages. Rice also has 5 members in the $\alpha$-tubulin family, and rice $\alpha$-tubulin 3 is most similar to group 1 in wheat. Paralogous rice $\alpha$-tubulins $1,2,4$, and 5 have higher amino acid sequence similarity among themselves than they do with wheat $\alpha$-tubulins (Fig. 1).

\section{Chromosome assignment of $\alpha$-tubulin genes}

Seven members of the $\alpha$-tubulin gene family ( $\alpha$-tubulins $1-3,2-3,3-3,4-3,5-1,5-2$, and 5-3) were mapped with gene-specific primers for PCR screening of chromosomal deletion stocks. Genetic stocks that did not yield PCR products indicate that the gene-family member is normally present on the missing chromosome or chromosome segment (Fig. 2). Ta_TUBA-1-3 is on chromosome 2D, Ta_TUBA-2-3 is on chromosome 1D, Ta_TUBA-3-3 is on chromosome 4D, Ta_TUBA-4-3 is on chromosome 5D, and Ta_TUBA-5-1, 52 , and 5-3 are on chromosomes 4A, 4B, and 4D, respectively. The chromosomal locations of these $\alpha$-tubulin genes were confirmed in the ditelosomic and deletion lines and found to be on chromosomes 2DS, 1DL, 4DS, 5DL, 4AL, 4BL, and 4DL, respectively (Fig. 3).

\section{$\alpha$-tubulin gene expression}

Expression of the 3 homeologous copies of $\alpha$-tubulin 3 (Ta-TUBA 3-1, 3-2, and 3-3) was measured over the time course of cold acclimation (up to $36 \mathrm{~d}$ ). Expression in response to cold was altered in the genes, and all 3 copies had similar changes in expression. The genes were downregulated after $1 \mathrm{~d}$ of cold treatment, had partial recovery of message levels after 3 and $6 \mathrm{~d}$, and had reduced levels again after 14 and $36 \mathrm{~d}$ of treatment (Fig. 4A). The other 4 paralogous members of the $\alpha$-tubulin gene family from the D genome ( $\alpha$-tubulins $1-3,2-3,4-3$, and 5-3) along with 3-3 were chosen to assay changes in gene expression; these were amenable to the design of gene-specific primers, and the expression of homeologs were expected to be similar in most cases, based on studies in other species (Adams et al. 2004) and as observed with the group-3 genes. These were assayed over a time course of $36 \mathrm{~d}$ of cold acclimation using RT-PCR. Each gene-family member had al- 
Fig. 3. Ditelosomic (A, B, E) and chromosome segment deletion (C, D, F, G) lines were used to determine the chromosome-arm location of 7 genes, including at least 1 from each of the paralogous groups of $\alpha$-tubulins, using PCR with gene-specific primers: (A) Ta_TUBA-1-3; (B) Ta_TUBA-2-3; (C) Ta_TUBA-3-3; (D) Ta_TUBA-4-3; (E) Ta_TUBA-5-3; (F) Ta_TUBA-5-1; and (G) Ta_TUBA-5-2.

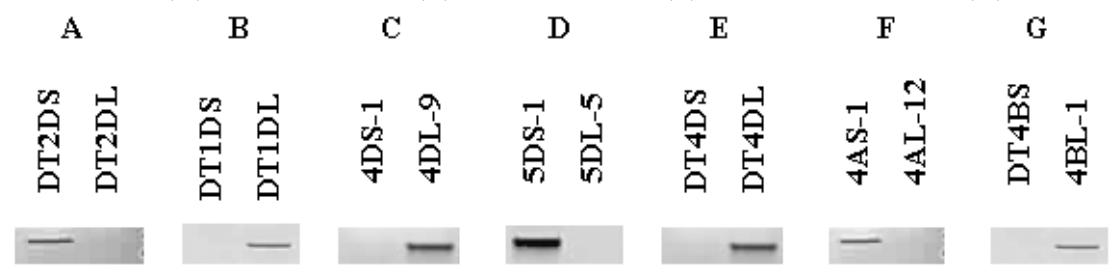

Fig. 4. Gene expression for $\alpha$-tubulins during cold acclimation. mRNA levels were measured with RT-PCR using gene-specific primers. Two sets of reactions were done to demonstrate that PCR did not saturate the set with the lower number of cycles. The highcycle set had 2 cycles of amplification more than the low-cycle set. (A) Three homeologous members from the same group (group 3), showing the same pattern of expression through cold acclimation. (B) The pattern of mRNA level of expression for $5 \alpha$-tubulin genes representing the 5 paralogous groups during $36 \mathrm{~d}$ of cold acclimation. Ubiquitin was used as an internal control.
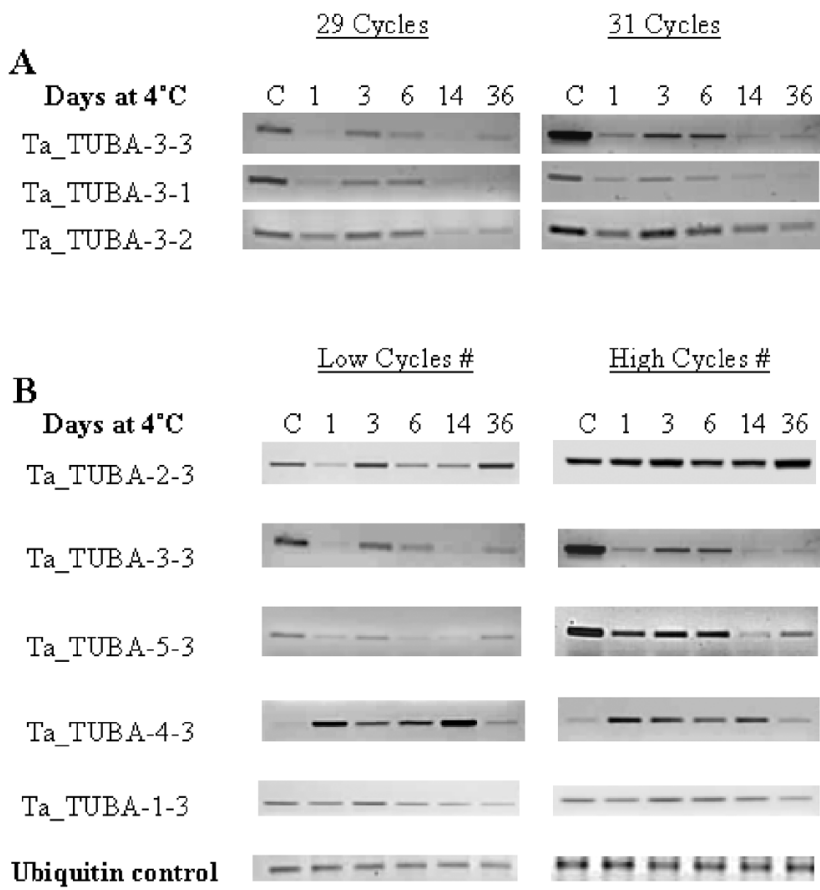

tered levels of mRNA in response to cold treatment (Fig. 4B), with 4 principal patterns of expression. The level of Ta_TUBA-2-3 mRNA decreased at day 1, increased at day 3, declined at days 6 and 14, and was strongly increased at day 36. Ta_TUBA-3-3 and Ta_TUBA-5-3 mRNA levels decreased at day 1 followed by an increase, a second decrease, and then a second increase during the $36 \mathrm{~d}$ time course. The Ta_TUBA-4-3 gene had a distinct pattern of expression; it had low levels of expression in the control plants and a strong induction at day 1 , modest declines at days 3 and 6, another increase at day 14, and low levels at day 36. The Ta_TUBA-1-3 gene had gradually declining levels of mRNA throughout the time course of cold acclimation.

The relative level of expression of gene-family members
Table 1. Relative abundance of $\alpha$-tubulin expressed sequence tags (ESTs) of Triticum aestivum.

\begin{tabular}{lcll}
\hline & $\begin{array}{c}\text { No. of } \\
\text { ESTs }\end{array}$ & $\begin{array}{l}\text { Homeolog } \\
\text { proportion }^{a}\end{array}$ & $\begin{array}{l}\text { Paralog } \\
\text { proportion }^{b}\end{array}$ \\
\hline Ta_TUBA-1-1 & 13 & 0.22 & \\
Ta_TUBA-1-2 & 20 & 0.33 & 0.02 \\
Ta_TUBA-1-3 & 27 & 0.45 & \\
Ta_TUBA-2-1 & 662 & 0.42 & \\
Ta_TUBA-2-2 & 381 & 0.24 & 0.61 \\
Ta_TUBA-2-3 & 530 & 0.34 & \\
Ta_TUBA-3-1 & 260 & 0.41 & \\
Ta_TUBA-3-2 & 235 & 0.37 & 0.24 \\
Ta_TUBA-3-3 & 137 & 0.22 & \\
Ta_TUBA-4-1 & 139 & 0.47 & \\
Ta_TUBA-4-2 & 41 & 0.14 & 0.11 \\
Ta_TUBA-4-3 & 115 & 0.39 & \\
Ta_TUBA-5-1 & 10 & 0.38 & \\
Ta_TUBA-5-2 & 12 & 0.46 & 0.01 \\
Ta_TUBA-5-3 & 4 & 0.15 & \\
\hline
\end{tabular}

${ }^{a}$ The proportion of ESTs for each gene-family member relative to the total number of ESTs for each homeologous group.

${ }^{b}$ The proportion of ESTs for each paralogous group relative to the total number of ESTs for $\alpha$-tubulins assigned to a specific gene-family member.

was measured by tabulating the number of corresponding ESTs in the GenBank EST database for T. aestivum. The data are summarized in Table 1. There were 2685 ESTs with at least $99 \%$ sequence identity with the wheat $\alpha$ tubulins that could be assigned to a specific gene-family member. The relative level of expression, reflected by the abundance in the EST database, varied widely among paralogous groups. The relatively rare sequences for $\alpha$-tubulin group 5 represented only $1 \%$ of the ESTs, whereas group-2 sequences represented $60 \%$ of the sequences. Groups 2 and 3 gene-family members, which are the most similar paralogous $\alpha$-tubulin genes in wheat, comprise $84 \%$ of all $\alpha$ tubulin ESTs. Comparison between homeologs indicates that the level of expression among homeologs is also variable, although the differences are subtler than those among paralogs. The representation of individual gene-family members within homeologous groups ranged from $14 \%$ to $47 \%$, a modest deviation from the $33 \%$ that would be predicted by equal representation of homeologs. There was no consistent genome of origin for the gene-family member with the highest or lowest level of expression in the different paralogous groups. 


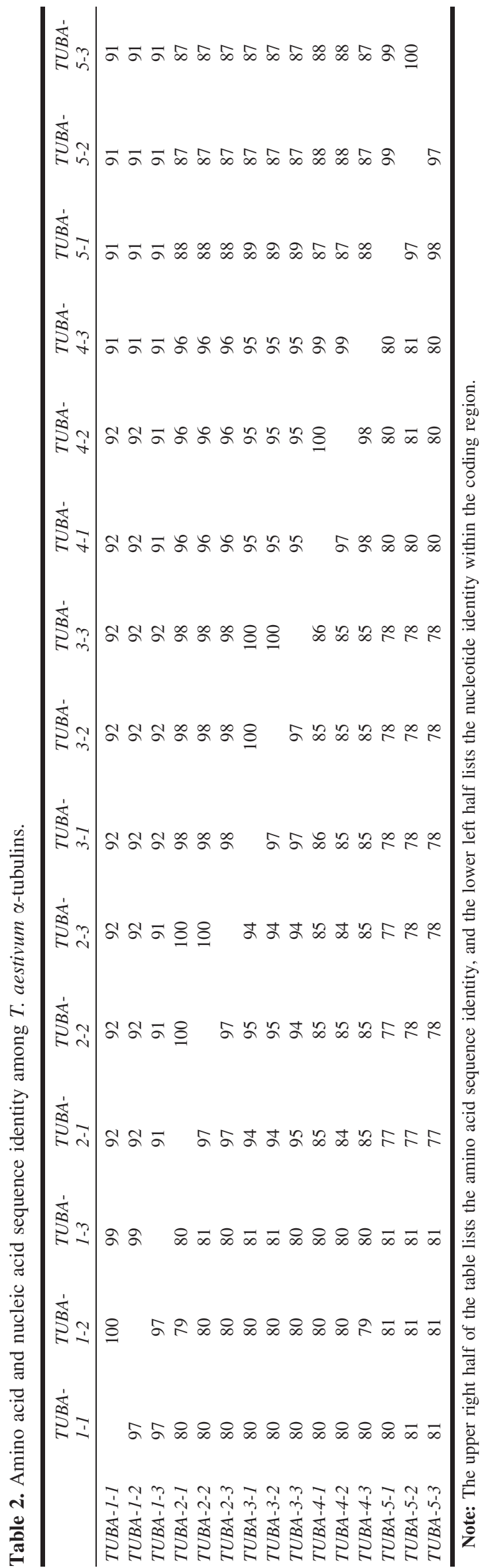

\section{Discussion}

The $\alpha$-tubulin gene family in wheat

The search for members of the $\alpha$-tubulin gene family in the wheat FGAS EST database for T. aestivum indicated that there were sequences for 15 members of the family. The $5 \alpha$-tubulin gene-family members identified in barley predict that hexaploid wheat has 15 gene-family members. Multiple-sequence alignment and construction of a similarity dendrogram grouped the gene-family members into 5 clusters, each with 3 members, corresponding to the homeologous genes from each of the donor genomes of T. aestivum (Fig. 1). When the barley $\alpha$-tubulin genes were included in the comparison, each cluster contained 1 member of the $\alpha$ tubulin gene family from barley. Members of the homeologous groups share 97\%-98\% nucleotide sequence identity within the coding region. The highest degree of sequence identity is between the groups for Ta_TUBA-2 and Ta_TUBA-3, which share $95 \%$ identity. The most diverged groups are Ta_TUBA-2 and Ta_TUBA-5, which share $77 \%$ sequence identity. Amino acid sequence identity within homeologous groups is between $99 \%$ and $100 \%$. Between homeologous groups, the highest degree of amino acid identity is $98 \%$ between the Ta_TUBA-2 and Ta_TUBA-3 groups; the most diverged groups, Ta_TUBA-2 and Ta_TUBA-5, have $87 \%$ sequence identity. The summary of gene identity is given in Table 2. The 97\%-98\% nucleotide sequence identity within homeologous sets is similar to the degree of similarity between the most similar gene-family members in wheat and barley. Rice and Arabidopsis, for which genomes have been fully sequenced, have 5 and 6 members of the $\alpha$ tubulin gene family, respectively. Sequence similarity among members of the gene family within each of those species is high, and although rice $\alpha$-tubulin 3 is most similar to wheat $\alpha$-tubulin group 1 , DNA sequence similarity does not give insight into orthology relationships between the other gene-family members in the Triticae and those in rice and Arabidopsis. Indeed, sequence similarity alone suggests that gene duplication occurred independently in the 3 lineages or that events such as gene conversion (Huang et al. 2003; Lassner and Dvorak 1986) have led to conservation or homogenization of sequences among duplicated genes within different lineages (Fig. 1).

\section{Chromosome assignment of $\alpha$-tubulin genes}

The classification of genes as paralogous members of the $\alpha$-tubulin gene family derived from sequence-similarity comparisons was confirmed by mapping 1 member of each homeologous group to a different chromosome arm. Genespecific primers were used to amplify DNA from a series of nulli-tetrasomic lines, which have 1 pair of deleted chromosomes replaced by a pair of homeologous chromosomes. Gene-specific primers for individual gene-family members were used to assign genes to specific chromosome arms by identifying specific chromosome-deletion stocks that did not yield a PCR product. In addition, the 3 members of group 5 were mapped to chromosome arms 4AL, 4BL, and 4DL. Chromosomal mapping data are summarized in Table 3. The study by Qi et al. (2004) identified chromosomes containing members of the tubulin family that are in agreement with the work reported here, although that work did not map individual gene-family members to specific chromosomes. 
Table 3. Genome assignment of T. aestivum $\alpha$-tubulins.

\begin{tabular}{|c|c|c|c|c|c|}
\hline $\begin{array}{l}\text { Tentative gene } \\
\text { ID }\end{array}$ & Genome & Gene & Mapping location & $\begin{array}{l}\text { Identity to Triticum } \\
\text { monococcum EST }\end{array}$ & $\begin{array}{l}\text { Identity to Triticum } \\
\text { turgidum EST }\end{array}$ \\
\hline Ta_TUBA-1-1 & A & $T U B A-1 A$ & & $98 \%$ & $99 \%$ \\
\hline Ta_TUBA-1-2 & B & $T U B A-1 B$ & & $97 \%$ & $99 \%$ \\
\hline Ta_TUBA-1-3 & $\mathrm{D}$ & $T U B A-1 D$ & Chromosome 2D & $97 \%$ & $97 \%$ \\
\hline Ta_TUBA-2-1 & A & $T U B A-2 A$ & & $99 \%$ & $99 \%$ \\
\hline Ta_TUBA-2-2 & B & $T U B A-2 B$ & & $98 \%$ & $99 \%$ \\
\hline Ta_TUBA-2-3 & $\mathrm{D}$ & $T U B A-2 D$ & Chromosome 1D & $97 \%$ & $97 \%$ \\
\hline Ta_TUBA-3-1 & A & $T U B A-3 A$ & & $98 \%$ & $99 \%$ \\
\hline Ta_TUBA-3-2 & $\mathrm{B}$ & $T U B A-3 B$ & & $98 \%$ & $99 \%$ \\
\hline Ta_TUBA-3-3 & $\mathrm{D}$ & $T U B A-3 D$ & Chromosome 4D & $98 \%$ & $97 \%$ \\
\hline Ta_TUBA-4-1 & A & $T U B A-4 A$ & & $99 \%$ & $99 \%$ \\
\hline Ta_TUBA-4-2 & B & $T U B A-4 B$ & & $97 \%$ & $97 \%$ \\
\hline Ta_TUBA-4-3 & $\mathrm{D}$ & $T U B A-4 D$ & Chromosome 5D & $97 \%$ & $97 \%$ \\
\hline Ta_TUBA-5-1 & A & $T U B A-5 A$ & Chromosome 4A & $83 \%$ & $100 \%$ \\
\hline Ta_TUBA-5-2 & B & $T U B A-5 B$ & Chromosome 4B & $83 \%$ & $97 \%$ \\
\hline Ta_TUBA-5-3 & $\mathrm{D}$ & $T U B A-5 D$ & Chromosome 4D & $83 \%$ & $97 \%$ \\
\hline
\end{tabular}

Note: The assignment to the genome was based on mapping to chromosome arms in cytogenetic stocks, and on sequence identity or the common presence of small deletions in the $3^{\prime}$ UTRs seen in expressed sequence tag (EST) sequences in T. monococcum or T. turgidum.

\section{Genome assignment of $\alpha$-tubulins}

The $T$. aestivum genome is one of the largest among major cereal crops because of its hexaploid nature and its high content of intergenic space, largely derived from retroposons. The assembly and annotation of the genome is a major challenge; most genes are expected to have at least 3 highly similar copies. The $\alpha$-tubulin gene family can serve as a model for the characterization of genes in homeologous series within wheat. The wheat EST sequence collection is one of the largest among plant species, with more than 855000 sequences at NCBI (Oct. 2006). The assembly of these sequences into contigs provides important insight into the nature of the wheat genome; however, the assembly of wheat sequences is especially tentative because of the presence of highly similar sequences originating from homeologous genes. The comparison of homeologs within the $\alpha$-tubulin gene family, which show consistent sequence identity of approximately $97 \%$ within the coding region, gives insight into parameters for gene-sequence assembly, especially when quality values for individual base calls in the sequences are not available.

The $97 \%$ sequence identity between homeologs in T. aestivum also facilitates the identification of the genome of origin for individual gene-family members. Several members of the $\alpha$-tubulin gene family are relatively highly expressed genes; thus, many of the orthologs of gene-family members can be found among ESTs from progenitor species, even though the size of the EST data sets for related species is modest. The genomes derived from the progenitor species are designated A, B, and $\mathrm{D}$. The $\mathrm{A}$ genome progenitor, Triticum urartu, is very closely related to Triticum monococcum (Huang et al. 2002), for which approximately 11190 EST sequences are available in GenBank. Triticum turgidum is the tetraploid donor of genomes A and B, and Aegilops tauschi is the $\mathrm{D}$ genome donor. There are approximately $10658 \mathrm{~T}$. turgidum and $130 \mathrm{~A}$. tauschii EST sequences in GenBank (October 2006). The sequences of many of the members of the $\alpha$-tubulin gene family have $99 \%$ sequence identity with EST sequences from T. monococcum and (or) T. turgidum, which allows the assignment of the most likely genome of origin for these genes. For example, Ta_TUBA2-1 has 99\% identity with T. monococcum and T. turgidum ESTs, indicating that it is likely the A genome copy. Ta_TUBA-2-2 has $96 \%$ identity with $T$. monococcum ESTs and $99 \%$ identity with T. turgidum, and Ta_TUBA-2-3 has 97\% identity with both T. monocuccum and T. turgidum; thus, the likely assignments of $\alpha$-tubulins 2-2 and 2-3 are to the $\mathrm{B}$ and $\mathrm{D}$ genomes, respectively. In 3 homeologous groups, 1 of the 3 members of each group showed higher sequence identity with a $T$. monococcum EST than the others. In the case of tubulins 3-1 and 3-2, both had 99\% identity with $T$. turgidum, but neither had $99 \%$ identity with a T. monococcum EST. However, the alignment of the 3 T. aestivum group-3 homeologs with the EST gi20314067 from T. monococcum showed perfect colinearity between the Ta_TUBA-3-1 and T. monococcum ESTs, whereas the other genes differed because of the presence of 3 large insertions or deletions and several single-nucleotide polymorphisms (SNPs) (supplementary data, Fig. S12). Ta_TUBA-3$l$ was thus assigned to the A genome. For group 5, it was not possible to determine the genome of origin for $\mathrm{Ta}_{-}$TUBA-5-1 or 5-2 using sequence comparison because only a single example of an ortholog for this group was found in T. turgidum and none were found in the T. monococcum EST databases. These genes were assigned genomes of origin $\mathrm{A}$ and $\mathrm{B}$, respectively, by mapping gene-family mem-

\footnotetext{
${ }^{2}$ Supplementary data for this article are available on the journal Web site (http://genome.nrc.ca) or may be purchased from the Depository of Unpublished Data, Document Delivery, CISTI, National Research Council Canada, Building M-55, 1200 Montreal Road, Ottawa, ON K1A 0R6, Canada. DUD 5168. For more information on obtaining material refer to http://cisti-icist.nrc-cnrc.gc.ca/irm/unpub_e.shtml.
} 
bers to specific chromosomes using chromosome-deletion stocks and gene-specific PCR primers. Gene names were assigned to the 15 wheat $\alpha$-tubulin genes based on the genome of origin, with the second digit of the clone name (1, 2, or 3) being replaced with $\mathrm{A}, \mathrm{B}$, or $\mathrm{D}$, respectively. The summary of gene similarity to ESTs from the 2 progenitor species, the genome assignment, and gene names are given in Table 3.

\section{The expression of $\alpha$-tubulin genes during cold acclimation}

Five genes representing each of the 5 homeologous groups were assayed for changes in mRNA levels during cold acclimation using RT-PCR analysis with gene-specific primers. Each $\alpha$-tubulin gene was found to be affected by cold treatment, and each gene had a distinct pattern of expression. Two of the genes, Ta_TUBA-3-3 and 5-3, showed a somewhat similar pattern of expression, which included reasonably high levels of expression under control conditions, an initial decrease in mRNA after $1 \mathrm{~d}$ of cold treatment followed by a rise after day 3, a decrease after days 6 and 14 , and a second increase after $36 \mathrm{~d}$ of cold acclimation. The Ta_TUBA-4-3 gene had a distinct pattern of expression that also included increases and decreases over the time course of treatment. The Ta_TUBA-1-3 had gradually declining levels of mRNA throughout the time course of cold acclimation (Fig. 4A). The differential expression of $\alpha$ tubulins during cold acclimation indicates that they play a role in cold acclimation and low-temperature tolerance.

The similar pattern of gene expression for the 3 homeologous copies of $T a \_T U B A-3$ is not surprising; investigation of gene expression patterns for homeologous pairs of genes in tetraploid cotton indicated that less than $10 \%$ of gene pairs showed evidence of gene silencing of one member of the pair (Adams et al. 2004). However, the comparison of the abundance of ESTs for specific gene-family members in the GenBank database indicates that there are subtle differences in levels of gene expression among homeologs within the gene family and large differences in levels of expression among paralogous groups.

The mRNA levels for the wheat protein kinase PK-F29 has been shown to be induced during cold acclimation (Gulick et al. 2005), and PK-F29 has been shown to interact specifically with Ta_TUBA-2-3 (Tardif et al. 2007). This $\alpha-$ tubulin gene also had cycles of induction and repression and had the most complex expression pattern among the family members tested. The rearrangement of microtubules in root cortical cells associated with the degree of cold tolerance and differential expression of $\alpha$-tubulin proteins has been reported by Abdrakhamanova et al. (2003); however, the amino acid sequence of the $\alpha$-tubulin gene sequences in our study indicates that the antibodies developed from rice $\alpha$ tubulins used by those researchers might not have been clearly gene-family member specific in wheat. We hypothesize that the changes in gene expression of the members of the $\alpha$-tubulin family are associated with the changing composition of microtubules and that this can subsequently influence the specific protein-protein interaction on the surface of microtubules. The study of protein-protein interaction on microtubules during cold acclimation warrants further investigation.

\section{Conclusion}

Fifteen $\alpha$-tubulin genes were identified in wheat. Sequence analysis clustered these into 5 homeologous groups that correspond to the 5 gene-family members identified in another member of the Triticae, $H$. vulgare. Each of the 5 representatives of the paralogous groups were found to be cold regulated and were mapped to 4 chromosomes in wheat. Ta_TUBA-2-3, which interacts with the coldregulated PK-F29, has a unique pattern of expression in that it cycles through induced and repressed levels of mRNA. This presents the possibility that one level of regulation of PK-F29 could be mediated by the regulation of its association with microtubules and its movement in the cell. This hypothesis is currently being investigated in localization studies, as is the confirmation of the specificity of the interaction of the cold-regulated PK-F29 and $\alpha$-tubulin family members.

\section{Acknowledgements}

We thank Wucheng Liu, Ani Dryanova, and Irina AlKhairi for valuable technical assistance. We thank Lasantha Ubayasena and Dr. Graham Scoles for the cytogenetic stocks used in this work. This work was supported by grants from the Natural Sciences and Engineering Research Council of Canada and by a Genome Canada, Genome Prairie, and Genome Quebec grant to P.J.G.

\section{References}

Abdrakhamanova, A., Wang, Q.Y., Khokhlova, L., and Nick, P. 2003. Is microtubule disassembly a trigger for cold acclimation? Plant Cell Physiol. 44: 676-686. doi:10.1093/pcp/pcg097. PMID:12881495.

Adams, K.L., Percifield, R., and Wendel, J.F. 2004. Organ-specific silencing of duplicated genes in a newly synthesized cotton allotetraploid. Genetics, 168: 2217-2226. doi:10.1534/genetics.104. 033522. PMID: 15371349 .

Camilleri, C., Azimzadeh, J., Pastuglia, M., Bellini, C., Grandjean, O., and Bouchez, D. 2002. The Arabidopsis TONNEAU2 gene encodes a putative novel protein phosphatase $2 \mathrm{~A}$ regulatory subunit essential for the control of the cortical cytoskeleton. Plant Cell, 14: 833-845. doi:10.1105/tpc.010402. PMID:11971138.

Chuong, S.D., Good, A.G., Taylor, G.J., Freeman, M.C., Moorhead, G.B., and Muench, D.G. 2004. Large-scale identification of tubulin-binding proteins provides insight on subcellular trafficking, metabolic channeling, and signaling in plant cells. Mol. Cell. Proteomics, 3: 970-983. PMID:15249590.

Dent, E.W., Tang, F., and Kalil, K. 2003. Axon guidance by growth cones and branches: common cytoskeletal and signaling mechanisms. Neuroscientist, 9: 343-353. doi:10.1177/ 1073858403252683 . PMID:14580119.

Endo, T.R., and Gill, B.S. 1996. The deletion stocks of common wheat. J. Hered. 87: 295-307.

Gilroy, S., and Trewavas, A. 2001. Signal processing and transduction in plant cells: the end of the beginning? Nat. Rev. Mol. Cell Biol. 2: 307-314. doi:10.1038/35067109. PMID:11283728.

Gulick, P.J., Drouin, S., Yu, Z., Danyluk, J., Poisson, G., Monroy, A.F., and Sarhan, F. 2005. Transcriptome comparison of winter and spring wheat responding to low temperature. Genome, 48: 913-923. PMID:16391697.

Huang, S., Sirikhachornkit, A., Su, X., Faris, J., Gill, B., Haselkorn, R., and Gornicki, P. 2002. Genes encoding plastid acetyl-CoA carboxylase and 3-phosphoglycerate kinase of the Triticum/Aegi- 
lops complex and the evolutionary history of polyploid wheat. Proc. Natl. Acad. Sci. U.S.A. 99: 8133-8138. doi:10.1073/pnas. 072223799. PMID:12060759.

Huang, L., Brooks, S.A., Li, W., Fellers, J.P., Trick, H.N., and Gill, B.S. 2003. Map-based cloning of leaf rust resistance gene $L r 21$ from the large and polyploid genome of bread wheat. Genetics, 164: 655-664. PMID:12807786.

Jian, L.C., Sun, L.H., and Liu, Z.P. 1989. Studies on microtubule cold stability in relation to plant cold hardiness. Acta Bot. Sin. 31: 737-741.

Lassner, M., and Dvorak, J. 1986. Preferential homogenization between adjacent and alternate subrepeats in wheat rDNA. Nucleic Acids Res. 14: 5499-5512. doi:10.1093/nar/14.13.5499. PMID:3737408.

Oono, Y., Seki, M., Satou, M., Iida, K., Akiyama, K., Sakurai, T., et al. 2006. Monitoring expression profiles of Arabidopsis genes during cold acclimation and deacclimation using DNA microarrays. Funct. Integr. Genomics, 6: 212-234. doi:10.1007/s10142005-0014-z. PMID:16463051.

Qi, L.L., Echalier, B., Chao, S., Lazo, G.R., Butler, G.E., Anderson, O.D., et al. 2004. A chromosome bin map of 16,000 expressed sequence tag loci and distribution of genes among the three genomes of polyploid wheat. Genetics, 168: 701-712. doi:10.1534/genetics.104.034868. PMID:15514046.

Rodriguez, O.C., Schaefer, A.W., Mandato, C.A., Forscher, P., Bement, W.M., and Waterman-Storer, C.M. 2003. Conserved microtubule-actin interactions in cell movement and morphogenesis. Nat. Cell Biol. 5: 599-609. doi:10.1038/ncb0703-599. PMID:12833063.

Sears, E. 1954. The aneuploids of common wheat. Missouri agricultural experiment station research bulletin $\mathbf{5 7 2}$.

Sears, E.R. 1966. Nullisomic-tetrasomic combinations in hexaploid wheat. In Chromosome manipulations and plant genetics. Edited by R. Riley and K.R. Lewis. Oliver and Boyd, Edinburgh. pp. 29-45.

Sears, E.R., and Sears, L.M.S. 1978. The telocentric chromosomes of common wheat. In Proceedings of the 5th International
Wheat Genetics Symposium, New Delhi, 23-28 February 1978. Edited by S. Ramanujam. Indian Society of Genetics and Plant Breeding, New Delhi. pp. 389-407.

Tardif, G., Kane, N.A., Adam, H., Labrie, L., Major, G., Gulick, P., et al. 2007. Interaction network of proteins associated with abiotic stress and development in wheat. Plant Mol. Biol. 63: 703-718. doi:10.1007/s11103-006-9119-6. PMID:17211514.

Thomashow, M.F. 1998. Role of cold-responsive genes in plant freezing tolerance. Plant Physiol. 118: 1-8. doi:10.1104/pp.118. 1.1. PMID:9733520.

Thomashow, M.F. 1999. Plant colc acclimation: freezing tolerance genes and regulatory mechanisms. Annu. Rev. Plant Physiol. Plant Mol. Biol. 50: 571-599. doi:10.1146/annurev.arplant.50.1. 571. PMID:15012220.

Thompson, J.D., Higgins, D.G., and Gibson, T.J. 1994. CLUSTAL W: improving the sensitivity of progressive multiple sequence alignment through sequence weighting, position-specific gap penalties and weight matrix choice. Nucleic Acids Res. 22: 4673-4680. doi:10.1093/nar/22.22.4673. PMID:7984417.

Tremblay, K., Ouellet, F., Fournier, J., Danyluk, J., and Sarhan, F. 2005. Molecular characterization and origin of novel bipartite cold-regulated ice recrystallization inhibition proteins from cereals. Plant Cell Physiol. 46: 884-891. doi:10.1093/pcp/pci093. PMID:15792959.

Wasteneys, G.O. 2003. Microtubules show their sensitive nature. Plant Cell Physiol. 44: 653-654. doi:10.1093/pcp/pcg103. PMID:12881491.

Wasteneys, G.O., and Galway, M.E. 2003. Remodeling the cytoskeleton for growth and form: an overview with some new views. Annu. Rev. Plant Biol. 54: 691-722. doi:10.1146/annurev. arplant.54.031902.134818. PMID:14503008.

Yan, L., Loukoianov, A., Tranquilli, G., Helguera, M., Fahima, T., and Dubcovsky, J. 2003. Positional cloning of the wheat vernalization gene VRN1. Proc. Natl. Acad. Sci. U.S.A. 100: 6263-6268. doi:10.1073/pnas.0937399100. PMID:12730378. 